Abstract IDDF2021-ABS-0037 Table 1 Patient demographics across period 1, period 2, period 3 and period $4(n=282)$

\begin{tabular}{|c|c|c|c|c|}
\hline Period & 1 & 2 & 3 & 4 \\
\hline Year & $2008-2010$ & $2011-2013$ & $2014-2015$ & $2016-2020$ \\
\hline Age $($ mean $\pm S D)$ & $48.1 \pm 12.2$ & $46.6 \pm 11.0$ & $45.3 \pm 12.3$ & $49.2 \pm 12.5$ \\
\hline Female & $17(47.2 \%)$ & $41(61.2 \%)$ & $40(60.6 \%)$ & $67(59.3 \%)$ \\
\hline Male & $19(52.8 \%)$ & $26(38.8 \%)$ & $26(39.4 \%)$ & $46(40.7 \%)$ \\
\hline \multicolumn{5}{|c|}{ Number treated according to treatment duration } \\
\hline 7-day & $10(27.8 \%)$ & $32(47.8 \%)$ & $\mathrm{n} / \mathrm{a}$ & $\mathrm{n} / \mathrm{a}$ \\
\hline 10-day & $26(72.2 \%)$ & $35(53.3 \%)$ & $66(100 \%)$ & $\mathrm{n} / \mathrm{a}$ \\
\hline 14-day & $\mathrm{n} / \mathrm{a}$ & $\mathrm{n} / \mathrm{a}$ & $\mathrm{n} / \mathrm{a}$ & $113(100 \%)$ \\
\hline \multicolumn{5}{|c|}{ Indications for endoscopy } \\
\hline Epigastric discomfort & $25(69.4 \%)$ & $58(86.6 \%)$ & $61(92.4 \%)$ & $104(92.0 \%)$ \\
\hline Chest pain & $3(8.3 \%)$ & $0(0.0 \%)$ & $0(0.0 \%)$ & $2(1.8 \%)$ \\
\hline Acid reflux \pm heartburn & $1(2.8 \%)$ & $0(0.0 \%)$ & $0(0.0 \%)$ & $3(2.7 \%)$ \\
\hline Anaemia & $1(2.8 \%)$ & $6(9.0 \%)$ & $2(3.0 \%)$ & $1(0.9 \%)$ \\
\hline Others & $6(16.7 \%)$ & $3(4.4 \%)$ & $3(4.6 \%)$ & $3(2.6 \%)$ \\
\hline \multicolumn{5}{|l|}{ Endoscopic diagnosis } \\
\hline Duodenal ulcer & $15(41.7 \%)$ & $15(22.4 \%)$ & $15(22.7 \%)$ & $22(19.5 \%)$ \\
\hline Gastritis & $12(33.3 \%)$ & $40(59.7 \%)$ & $42(63.6 \%)$ & $69(61.0 \%)$ \\
\hline Gastric ulcer & $2(5.6 \%)$ & $3(4.48 \%)$ & $1(1.5 \%)$ & $4(3.5 \%)$ \\
\hline Normal & $5(13.9 \%)$ & $8(11.9 \%)$ & $7(10.6 \%)$ & $9(8.0 \%)$ \\
\hline Others & $2(5.5 \%)$ & $7(10.5 \%)$ & $1(1.5 \%)$ & $9(8.0 \%)$ \\
\hline
\end{tabular}

$\begin{aligned} & \text { Abstract IDDF2021-ABS-0037 Table } 2 \\
& \text { rates over Period 1,2 and 3 }\end{aligned}$
\begin{tabular}{llllll}
\hline Period & Year & $\begin{array}{l}\text { Treatment } \\
\text { duration (days) }\end{array}$ & $\begin{array}{l}\text { Number } \\
\text { treated }\end{array}$ & $\begin{array}{l}\text { Eradication } \\
\text { rate (\%) }\end{array}$ & $\begin{array}{l}\text { Overall } \\
\text { eradiction (\%) }\end{array}$ \\
\hline $\mathbf{1}$ & $2008-10$ & 7 & 10 & 90.0 & 94.4 \\
& & 10 & 26 & 96.0 & \\
2 & $2011-13$ & 7 & 32 & 84.3 & 85.1 \\
& & 10 & 35 & 85.7 & \\
3 & $2014-15$ & 10 & 66 & 80.3 & 80.3 \\
\hline
\end{tabular}

Abstract IDDF2021-ABS-0037 Table 3 Comparison of the eradication rates between 10-day (Period 3) and 14-day (Period 4) treatment

\begin{tabular}{lcllll}
\hline Period & Year & $\begin{array}{l}\text { Treatment } \\
\text { duration (days) }\end{array}$ & $\begin{array}{c}\text { Number } \\
\text { treated }\end{array}$ & $\begin{array}{l}\text { Eradication } \\
\text { rate (\%) }\end{array}$ & p value \\
\hline 3 & $2014-15$ & 10 & 66 & 80.3 & \\
4 & $2016-20$ & 14 & 113 & 91.1 & $0.036^{*}$ \\
\hline *Statistical significance noted when comparing period 3 and 4
\end{tabular}

Results 282 patients (165 female, 117 male; mean age \pm standard deviation, $47.5 \pm 12.1$ years; range, 19-78 years old) with follow-up data were included in the study. A trend of decreasing eradication rates was observed from 2008 to 2015 $(p=0.026)$. These results are demonstrated in Table 2 (IDDF2021-ABS-0037 Table 2). Increasing the duration of treatment from 10 days to 14 days was found to achieve a significantly higher $H$. pylori eradication rate between 2016 to
2020. $(p=0.032)$. This is reflected in the findings in Table 3 (IDDF2021-ABS-0037 Table 3).

Conclusions Clarithromycin-based triple therapy remains an effective first-line therapy for $\mathrm{H}$. pylori eradication in Hong Kong, but a treatment duration of 14 days should be given instead of 7 or 10 days.

\section{IDDF2021-ABS-0039 IDENTIFYING PATIENTS WITH CROHN'S DISEASE AT HIGH RISK OF PRIMARY NONRESPONSE TO INFLIXIMAB THERAPY USING A RADIOMIC-CLINICAL NOMOGRAM}

${ }^{1}$ Xuehua Li*, ${ }^{2}$ Yingkui Zhong, ${ }^{3}$ Bingsheng Huang, ${ }^{1}$ Ziping Li, ${ }^{1}$ Baili Chen. ${ }^{1}$ The First Affiliated Hospital, Sun Yat-Sen University, China; ${ }^{2}$ The Sixth Affiliated Hospital, Sun Yat-Sen University, China; ${ }^{3}$ Medical Al Lab, School of Biomedical Engineering, Health Science Center, Shenzhen University, China

\subsection{6/gutjnl-2021-IDDF.116}

Background 13\%-40\% of patients with Crohn's disease (CD) show a primary loss of response to infliximab therapy. This study aimed to develop and validate a novel radiomic-clinical nomogram to identify $\mathrm{CD}$ patients at high risk of primary nonresponse to infliximab therapy.

Methods This retrospective study included 224 CD patients (training, $\mathrm{n}=118$; test $1, \mathrm{n}=52$; test $2, \mathrm{n}=54$ ) recruited from one of the two-three tertiary referral centers. The computed tomography enterography (CTE) and clinical data before infliximab treatment of CD patients were collected and the outcome of infliximab induction therapy at week 14 was classified as response or primary nonresponse. In the training cohort, 1130 radiomics features were extracted from the whole inflamed gut of CD patients on arterial-phase CTE; Least absolute shrinkage and selection operator and support vector machine methods were performed to select key features and construct a radiomics signature; moreover, a clinical factors model was developed based on the selected clinical risk factors. Subsequently, a radiomic-clinical nomogram which integrated the radiomics signature and the selected clinical predictors was developed based on a multivariable logistic regression analysis. The predicting performance of this nomogram was validated in two external independent test cohorts.

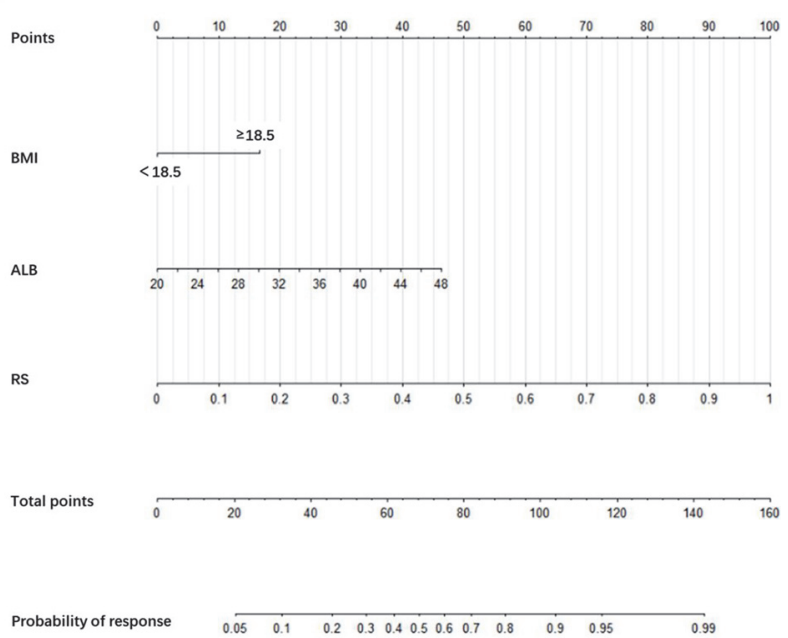

Abstract IDDF2021-ABS-0039 Figure 1 

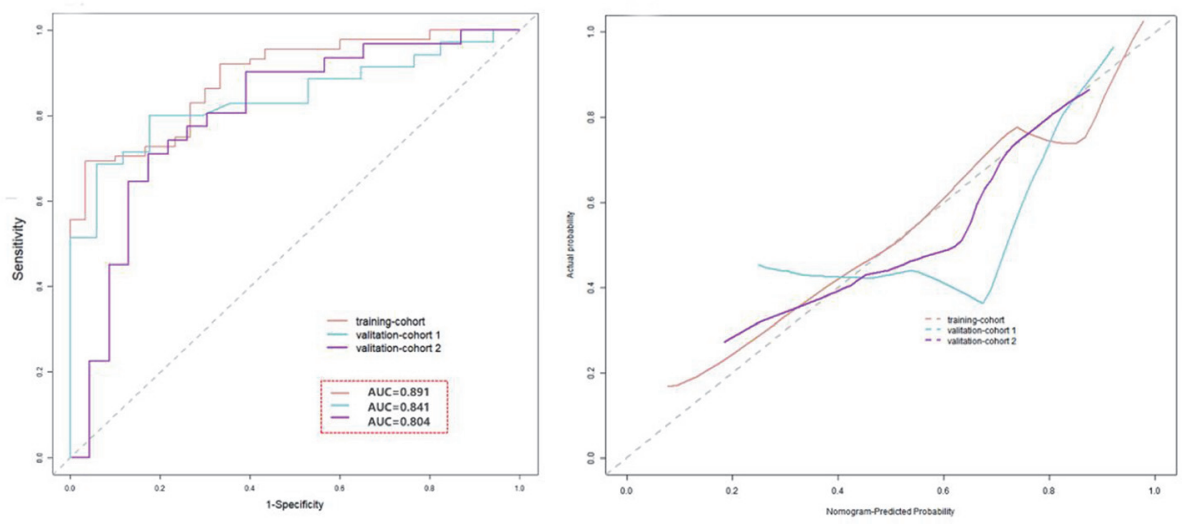

\section{Abstract IDDF2021-ABS-0039 Figure 2}

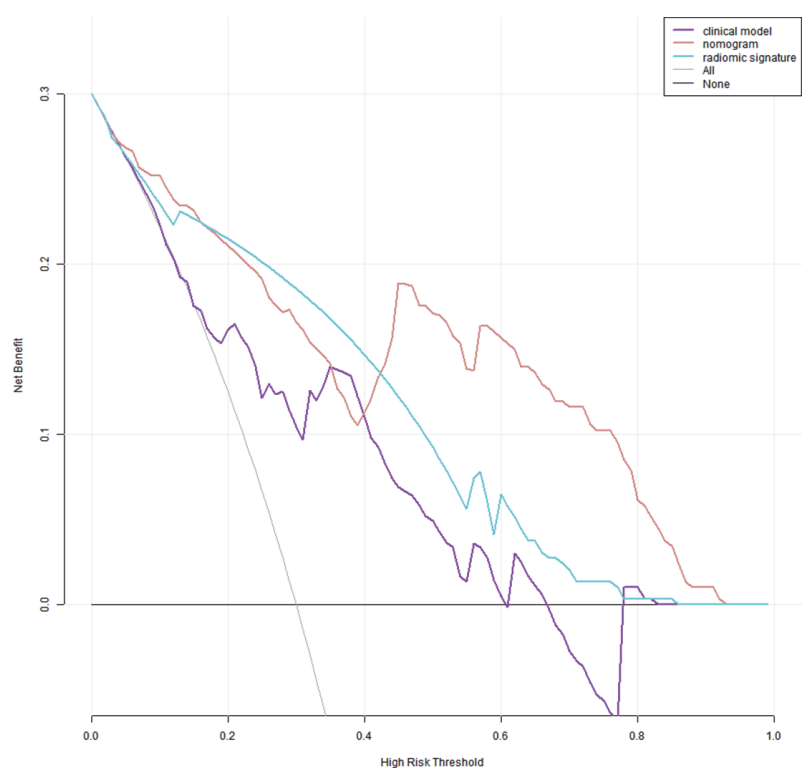

\section{IDDF2021-ABS-0044 COMPARABLE EFFICACY OF CURCUMIN AND PROTON PUMP INHIBITOR FOR FUNCTIONAL DYSPEPSIA: A RANDOMIZED DOUBLE-BLINDED CONTROLLED TRIAL}

${ }^{1}$ Wichittra Khongkha*, ${ }^{2}$ Pradermchai Kongkam, ${ }^{2}$ Krit Pongpirul, ${ }^{2}$ Prach Kosarussawadee, ${ }^{2}$ Phanupong Phutrakool, ${ }^{3}$ Sittichai Khamsai, ${ }^{3}$ Kittisak Sawanyawisuth, ${ }^{4}$ Thanyachai Sura, ${ }^{5}$ Pochamana Phisalprapa, ${ }^{6}$ Thanwa Buamahahkul, ${ }^{2}$ Sarawut Siwamogsatham, ${ }^{7}$ Kulthanit Wanaratna, ${ }^{7}$ Jaenjira Angsusing, ${ }^{7}$ Monthaka Teerachaisakul. ${ }^{1}$ Chao Phraya Abhaibhubejhr Hospital, Thailand; ${ }^{2}$ Chulalongkorn University Faculty of Medicine, Thailand; ${ }^{3}$ Khon Kaen University, Thailand; ${ }^{4}$ Ramathibodi Hospital, Thailand; ${ }^{5}$ Siriraj Hopsital, Thailand; ${ }^{6}$ Ratchaburi Hospital, Thailand; ${ }^{7}$ Department of Thai Traditional and Alternative Medicine, Ministry of Public Health, Thailand

\subsection{6/gutjnl-2021-IDDF.117}

Background Curcumin has been claimed to have gastrointestinal benefits including dyspepsia-a common disorder that could be managed in a primary care setting with behavioral and dietary modification as well as over-the-counter medications. This study aimed to compare the efficacy of curcumin versus omeprazole in improving patient-reported outcomes.

Methods This randomized controlled trial comprised of three arms of four large (250 mg of curcumin or placebo) and one small (20 mg of omeprazole or placebo) capsules: curcumin only (C), omeprazole only $(\mathrm{O})$, and curcumin+omepraazole $(\mathrm{C}+\mathrm{O})$. The large capsules were taken four times daily and the small capsules were taken twice daily for 28 days. Eligible participants with dyspepsia symptoms, assessed by using the Short-Form Leeds Dyspepsia Questionnaire (SFLDQ), underwent gastroscopy by certified gastroenterologists; those with pathologic dyspepsia including Helicobacter pylori infection were excluded. Functional dyspepsia symptoms were assessed by using the Severity of Dyspepsia Assessment (SODA) scores at baseline, day 28, and day 56. Demographics and clinical characteristics were analyzed by using descriptive statistics. Comparative improvement of SODA scores across the three arms, adjusted for potential confounders, were analyzed by using generalized estimating equations (GEE) regression.

Results A total of 207 participants; C (69), O (69), C+O (69), were recruited, of which 151; C (49), O (49), C+O (53) completed the study. The overall mean age was 49.7 \pm 11.9 years and $73.4 \%$ were female. Demographics, clinical characteristics, baseline SODA, and SF-LDQ scores were comparable across the three groups. The SODA pain intensity reduction $(\mathrm{C}$ : -6.22 and -9.59 ; $\mathrm{O}$ : -6.98 and $-10.62 ; \mathrm{C}+\mathrm{O}$ :
Conclusions The radiomic-clinical nomogram may be a promising tool to allow accurately identify CD patients at high risk of primary nonresponse to infliximab therapy. 